\title{
Tecendo relações entre a disciplina de didática, a universidade e o contexto escolar
}

\author{
Osmar Hélio Alves Araújo * \\ Luís Távora Furtado Ribeiro**
}

\section{Resumo}

Neste artigo, parte-se do pressuposto de que a disciplina de Didática deve proporcionar aos estudantes das licenciaturas uma dinâmica cognitiva/ social/política necessária à construção de aprendizagens significativas a respeito da docência. O contexto em que essa discussão está inserida foi o Curso de Letras da Universidade Regional do Cariri (URCA), Campus Missão Velha (CE), com foco na disciplina de Didática. Em relação aos procedimentos didáticos, pautou-se na pesquisa-ação-colaborativa (PIMENTA, 2005). A Didática deve contribuir para que os professores desenvolvam atitude crítica-reflexiva como condição básica para a construção de conhecimentos pedagógicos integrados ao contexto escolar.

Palavras-chave: Didática. Pedagogia. Formação docente. Contexto escolar.

* Universidade Regional do Cariri (URCA)/Universidade Federal da Paraíba (UFPB). Doutorando em Educação pela Universidade Federal da Paraíba (UFPB); mestre em Educação pela Universidade Federal do Ceará (UFC); graduando em Pedagogia; graduado em Letras; especialista em Supervisão e Orientação Educacional pela Universidade Cidade de São Paulo (UNICID).

** Universidade Federal do Ceará - UFC. Possui graduação em Ciências Sociais pela Universidade Federal do Ceará (1983); mestrado em Educação pela Universidade Federal do Ceará (1990) e doutorado em Sociologia pela Universidade Federal do Ceará (2002). 


\title{
Constructing relationships between the didactics subject, the university and the school context
}

\begin{abstract}
In this article, it is assumed that the Didactics subject should provide Bachelor students with the cognitive/social/political dynamics necessary to construct meaningful learning concerning teaching. The context in which this discussion is inserted is the Letters Course at the Regional University of Cariri (URCA), Missão Velha Campus (CE), with a focus on Didactics. Regarding didactic procedures, the study was based on action-collaborative research (PIMENTA, 2005). Didactics should contribute to the development of critical-reflexive teacher attitudes as a basic condition for the construction of pedagogical knowledge integrated into the school context.
\end{abstract}

Keywords: Didactics. Pedagogy. Teacher training. School context.

\section{Tejiendo relaciones entre la materia de didáctica, la universidad y el contexto escolar}

\section{Resumen}

En este artículo, se parte del presupuesto de que la materia Didáctica debe proporcionar a los estudiantes de las licenciaturas una dinámica cognitiva/ social/política necesaria para la construcción de aprendizajes significativos con respecto a la docencia. El contexto en que esta discusión se ubica fue la Carrera de Letras de la Universidad Regional do Cariri (URCA), Campus Missão Velha (CE), con foco en la materia de Didáctica. En relación a los procedimientos didácticos, se pautó realizar una investigación-acción-colaborativa (PIMENTA, 2005). La Didáctica debe contribuir a que los profesores desarrollen una actitud crítico-reflexiva como condición básica para la construcción de conocimientos pedagógicos integrados al contexto escolar. Palabras clave: Didáctica. Pedagogía. Profesores. Contexto escolar.

\section{Considerações iniciais}

A Pedagogia, como ciência da educação, volta-se essencialmente para a práxis educativa. A Pedagogia, a nosso ver, possui gramática própria, clara epistemologia de inclusão, de emancipação do homem e de transformação do meio social. A Didática está voltada para a fundamentação e compreensão dos processos de ensino 
e aprendizagem. A formação dos professores, por consequência, precisa ser construída de modo articulado à Pedagogia e à Didática, para que os professores possam construir e reconstruir a ação de ensinar-aprender por meio da reflexão crítica de pensar a prática a partir da própria prática em suas múltiplas nuanças (ARAÚJO; RODRIGUES; ARAGÃO, 2017).

A disciplina de Didática, e as demais disciplinas dos diversos cursos de licenciatura, devem proporcionar aos estudantes uma experiência de reflexão e compreensão da docência a partir, sobretudo, da realidade das escolas públicas brasileiras. Além disso, devem incentivá-los ao compromisso com a aprendizagem da profissão e com a construção de uma educação pública de qualidade. Trata-se do desenvolvimento de uma formação docente "[...] pensada e realizada a partir da função social própria à educação básica, à ESCOLA e os processos de escolarização [...]" (GATTI, 2013, p. 59, grifos da autora).

Aranha e Souza (2017, p. 83) sublinham que os "Jovens estudantes de licenciatura não conhecem da escola básica quase nada além do que apreenderam dela como estudantes que foram outrora". Convém enfatizar a importância da disciplina de Didática como espaço de ação-reflexão-ação, do exercício da práxis, ou seja, do método da dialética. Pois, "A práxis é ativa, é vida, dá movimento à realidade, transforma-a e é por ela transformada" (FRANCO, 2008, p. 82).

Neste artigo, discute-se a necessária relação entre a disciplina de Didática nos diversos cursos de licenciatura e as escolas básicas brasileiras. Como diz Candau (2016, p. 312), “[...] a formação docente deve se dar em parceria entre a universidade e a escola básica: seu centro deve ser a prática profissional”. Essa discussão emergiu, sobretudo, do exercício docente no Ensino Superior, mais precisamente, no campo da pesquisa em educação e, por isso, está articulada à atuação de formação e profissional, com foco na disciplina de Didática, no Curso de Letras da Universidade Regional do Cariri (URCA), ${ }^{1}$ Campus Missão Velha (CE).

1 Nas seções seguintes da discussão, será utilizada a sigla URCA para fazer referência à Universidade Regional do Cariri, Campus Missão Velha (CE), 
Os procedimentos didáticos, por meio da pesquisa-ação-colaborativa (PIMENTA, 2005), sustentaram-se no ensino, na pesquisa e na extensão. ${ }^{2}$ Isso se deu devido ao fato de que, em tempo paralelo às aulas específicas da disciplina de Didática, dois projetos de extensão, um projeto de iniciação científica e um projeto de monitoria, relacionados à formação e às práticas docentes da escola básica, foram desenvolvidos visando construir um contexto de formação docente em rede, universidade e escolas básicas.

A pesquisa-ação-colaborativa permite uma visão do que ocorre por dentro do fenômeno estudado, posto que leva em consideração os componentes de uma situação e suas interações e influências recíprocas. Nesse processo, a problematização, o diálogo e a reflexão da prática na prática possibilitarão a formação dos sujeitos envolvidos no próprio contexto de formação/trabalho.

Os estudantes das licenciaturas, a partir da experiência vivenciada na disciplina de Didática, precisam compreender a importância do professor pesquisador, aquele que rompe com o estabelecido e busca novas respostas às teorias a partir da realidade do aluno. Os estudantes devem ter a consciência da sua necessária responsabilidade diante da sua formação e do compromisso com a educação pública brasileira, ainda muito carente de um trabalho sério, e de práticas educativas que contribuam para a construção de uma sociedade mais humanizada.

enquanto contexto da experiência em questão. Conforme consta no Projeto Político Pedagógico do curso do Letras (PPP, 2013), a Universidade Regional do Cariri-URCA foi criada pela Lei Estadual No. 11.191, de 9 de junho de 1986, com sede na cidade do Crato e atuação em diversos municípios da região sul e centro-sul do Ceará.

2 Projetos de Extensão 01: "A inserção da leitura na formação dos licenciandos do Curso de Letras e na formação contínua dos docentes da educação básica"; 02: "Metáfora do quebra-cabeça: ensino e pesquisa na formação docente". Projeto de Iniciação Científica: 01: "A formação didático-pedagógica nos Cursos de Letras e Ciências Biológicas da URCA: vacina de conforto pedagógico?". Por último, o Projeto de Monitoria: “Tecendo relações entre a Didática, a Universidade e o Contexto escolar: territórios em diálogo”. 
Uma educação pública, de fato, de qualidade é resultado de um trabalho construído a muitas mãos e, acima de tudo, com condições materiais, infraestruturais e recursos humanos preparados em todos os níveis e instâncias do ensino. A disciplina de Didática, portanto, deve proporcionar aos futuros professores reflexões da prática na prática, assim como ações educativas que contribuam para a melhoria dos resultados dos processos de ensino e aprendizagem nas escolas básicas brasileiras. Como diz Libâneo (2007, p. 45), "Desde o ingresso dos alunos no curso [licenciaturas], é preciso integrar os conteúdos das disciplinas em situações da prática que coloquem problemas aos futuros professores e lhes possibilitem experimentar soluções, com a ajuda da teoria".

Concordando com Araújo e Rodrigues (2018), a formação dos professores deve ser um processo sempre em construção e que contribui para a dignidade, a profissionalização e o desenvolvimento contínuo, pessoal e profissional docente. Por isso, faz-se necessário diminuir a distância, estreitar a relação entre a universidade e as instituições escolares básicas de modo a construir uma formação docente verdadeiramente plena de sentido e integrada à ação de ensinar-aprender na educação básica brasileira. A Didática, nesta relação/ integração, universidade e escolas básicas, torna-se uma exigência imprescindível para a construção de processos e espaços de ressignificação e renovação da docência e para uma práxis pedagógica renovada.

\section{A disciplina de didática e o contexto escolar: diá- logos e possibilidades}

No Brasil, há resquícios da insuficiente formação didático -pedagógica nos cursos de licenciatura, pois o modelo de formação conservadora dos professores, que se pautavam na tendência liberal tecnicista $^{3}$ (LIBÂNEO, 2008), parece ainda nortear os cursos de licenciatura. Ilustra essa ideia o depoimento que segue:

Segundo Pereira (1999), na formação dos professores a ênfase era em técnicas e métodos e se ancorava na conhecida fórmula “ $3+1$ ”, em que as disciplinas de cunho pedagógico justapunham-se às disciplinas de conteúdo. 
O curso de licenciatura em si não oportuniza uma formação didática-pedagógica. Acredito que minha formação pedagógica para exercer a docência se dará a partir da minha experiência em sala de aula, a partir do momento que eu começar a exercer a docência. Agora se tratando das disciplinas especificas, aprendi muito na minha licenciatura. ${ }^{4}$

Os diversos cursos de licenciatura apresentam uma carga horária contraproducente em relação aos aspectos didático-pedagógicos, posto que “[...] a formação pedagógica, quando não é vista como inteiramente desnecessária, é apenas tolerada como um verniz cultural, já que o essencial da formação "[...], é o domínio dos conteúdos específicos de cada área” (ARANHA; SOUZA, 2017, p. 81). É perceptível a problemática que permeia os cursos de licenciatura, a partir dos quais, na maioria das vezes, os profissionais da educação concluem sua formação inicial sem uma necessária formação pedagógica.

Gatti (2013), Aranha e Souza (2017) evidenciam que, nos cursos de licenciatura, a formação pedagógica oferecida reduz-se a algumas disciplinas, habitualmente com uma carga horária média de 60 horas, 90 horas, muitas vezes, notadamente teóricas e desligadas da prática. Endossa o exposto o depoimento que segue:

A formação didática-pedagógica que o curso de licenciatura oportuniza não é producente, haja vista que temos poucas disciplinas que visam à didática, à formação pedagógica em si, pois, essas disciplinas são bem pontuais e não dá para aprender muita coisa não. ${ }^{5} \mathrm{Em}$ contrapartida, a Didática e a Pedagogia podem indicar vias, propor e exercer forte influência para se desdenhar a precariedade pedagógica que permeia a formação docente. Os referidos campos do conhecimento permitirão aos estudantes das licenciaturas compreender os diversos elementos que compõem o processo educativo, assim como empreender possíveis mudanças na cultura escolar, nas práticas pedagógicas, e, ainda, estabelecer uma relação entre a formação ora vivenciada e as práticas pedagógicas construídas e em

4 Informação verbal colhida nos momentos de avaliação das atividades realizadas na disciplina de Didática, dez. 2016.

5 Informação verbal colhida nos momentos de avaliação das atividades realizadas na disciplina de Didática, dez. 2016. 
construção nas escolas básicas brasileiras. Como explica Libâneo (2007, p. 45), é preciso “[...] ter a prática [...] para contrastar seus estudos e formar seus próprios conhecimentos e convicções. Isso quer dizer que os alunos precisam conhecer o mais cedo possível os sujeitos e as situações com que irão trabalhar".

A Pedagogia direciona pedagogicamente o processo educativo, atribuindo caráter político e social, de modo correlato, a um projeto de sociedade que se deseja construir. É evidente a relevância dos aspectos didático-pedagógicos na formação inicial do professor, de modo que esse profissional tenha subsídio teórico-prático do campo pedagógico para o entendimento e direcionamento da ação de ensinar-aprender. Em linhas gerais, a Pedagogia e a Didática são componentes constitutivos da formação e da construção da identidade docente. A Pedagogia, associada ao caráter formativo da didática, possibilita a mobilização e a construção de saberes pedagógicos, bem como, permite aos professores criarem e recriarem suas práticas com protagonismo e militância pedagógica (ARAÚJO; RODRIGUES; ARAGÃO, 2017).

A formação inicial dos professores, portanto, deve ser um processo que valoriza a formação docente não mais pautada na racionalidade técnica, que considera os professores como meros executores de decisões alheias. Ao contrário, essa formação deve se pautar em uma perspectiva que os reconhece como sujeitos capazes de decidir, construir, transformar e, sobretudo, “[...] como sujeito aprendiz, futuro profissional e cidadão, que atuará e transformará, de forma mais ou menos engajada e criativa, a realidade em que viverá” (PIMENTA; ANASTASIOU, 2002, p. 29).

A formação didático-pedagógica nos cursos de licenciatura deve possibilitar aos estudantes entrecruzar a teoria e a prática de sala de aula e fornecer subsídios teóricos-metodológicos para a futura atuação profissional nos diferentes níveis de ensino aos quais se destinam. Por isso, os cursos de licenciatura podem e precisam pautar-se no campo da Pedagogia e da Didática de modo a possibilitar aos estudantes, parafraseando Aranha e Souza (2017), 
conhecer da escola básica muito além do que apreenderam dela enquanto estudantes, assim como conhecer os desafios, movimentos e possibilidades de formação no contexto da universidade versus o contexto escolar.

Entretanto, os diferentes cursos de licenciatura, na maioria das vezes, não constroem uma formação docente atrelada à educação básica. Há ausência de elementos teóricos e práticos nas disciplinas específicas, pois o "[...] o currículo da educação básica praticamente não aparece [...]" (GAT'TI, 2013, p. 58) no plano dessas disciplinas. De modo mais específico, o Curso de Letras da URCA se encontra na mesma direção, posto que as disciplinas específicas do Curso de Letras, como Teoria da Literatura, Linguística Aplicada ao Ensino do Português, Políticas Educacionais, entre outras, (PPP, 2013), não se voltam para o trabalho pedagógico da escola básica. Os depoimentos que seguem corroboram o exposto:

São inúmeras as dificuldades e problemas em relação à nossa formação inicial, pois consigo elencar com facilidade as lacunas pedagógicas deixadas pelo curso de licenciatura, como: desconexo com a escola, educação básica, falta de leituras pedagógicas que nos leve a compreender os elementos que compõem os processos de ensino e aprendizagem, assim como a ausência de práticas de pesquisa tomando as escolas públicas como lócus de formação. ${ }^{6} \mathrm{O}$ curso de licenciatura não oferece a formação pedagógica necessária, pois é como se nos formasse de modo alheio às escolas públicas. Então, eu percebo que não temos muito conhecimento didático-pedagógico, principalmente acerca dos processos de ensino e aprendizagem em suas diferentes dimensões.

Conforme informações do Projeto Político Pedagógico do curso de Letras da URCA (PPP, 2013), a Didática, como disciplina do eixo articulador da teoria e da prática, perfaz um total de $90 \mathrm{~h} / \mathrm{a}$, e é alocada no VI semestre do curso. De modo específico, no plano

Informação verbal colhida nos momentos de avaliação das atividades realizadas na disciplina de Didática, dez. 2016.

7 Informação verbal colhida nos momentos de avaliação das atividades realizadas na disciplina de Didática, dez. 2016. 
de disciplina de Didática, no item 4: Metodologia de ensino, há a seguinte observação:

Nesta disciplina, torna-se essencial o trabalho de visita às instituições de ensino para fins de reconhecimento do espaço físico, observação de aulas, percepção das filosofias pedagógicas de cada estabelecimento visitado. Essas observações serão registradas no Portfólio (PPP, 2013, p. 164).

Essa observação, restrita ao Plano de disciplina de Didática, deixa entrever a ausência de elementos teóricos e práticos nas disciplinas específicas. Portanto, o trabalho de inserção dos estudantes das licenciaturas em um exercício de reflexão, ação-reflexão-ação, do exercício da práxis nas escolas públicas brasileiras, é, muitas vezes, esparsamente desenvolvido em detrimento do conteúdo puramente teórico. Por isso, na maioria das vezes, os cursos de licenciatura restringem-se a um permanente "convite" à reflexão sobre a docência na educação básica e, por consequência, os professores são formados “[...] de modo não reflexivo, não dialógico, desconhecendo os mecanismos e movimentos da práxis” (FRANCO, 2015, p. 607).

É oportuno reiterar a defesa de uma formação docente a partir da articulação entre o processo formativo (Didática/universidade) e o exercício da docência (escola básica) que, como desdobramento, possibilite uma experiência formativa/docente peculiar e constitua-se como um contexto de cultura viva, política, cujo intento seja a construção de novos rumos para a formação dos professores e para a sociedade.

As escolas públicas necessitam, muitas vezes, de professores que atuem pedagogicamente como mediadores e instigadores de uma cultura que leve seus diferentes sujeitos a perceberem que a referida instituição pode e precisa ser transformada.

A disciplina de Didática, nessa perspectiva, deve inserir os estudantes das licenciaturas no contexto escolar por meio de atividades de pesquisas, pois a escola básica configura-se predominantemente como um lugar de referência do "saber-fazer", ou seja, apresenta-se como lócus de formação por excelência. A referi- 
da disciplina deve ter como objetivo levar os discentes a analisar/ aprofundar os elementos teórico-metodológicos, contextuais e históricos da docência na educação básica, a partir da compreensão da Didática como elemento mediador dos processos de ensino e aprendizagem. Metodologicamente, essa disciplina deve se apoiar na perspectiva da pesquisa participante, haja vista que os discentes deverão estar presentes, agindo como observadores/participantes do contexto escolar.

No contexto dessa discussão, parafraseando Rios (2014), a disciplina de Didática, em uma perspectiva de pesquisa observação / participante, deve constituir-se como espaço de partilha de ideias, de levantamento de questões e busca de descobertas e especificidades. Para isso, o diálogo deve estar presente, assim como "[...] a humildade, como reconhecimento do que não se sabe, e a coragem, como enfrentamento dos obstáculos e busca de instrumentos para superá-los e caminhar na direção do saber" (RIOS, 2014, p. 119).

Há necessidade, portanto, de que os estudantes das licenciaturas reivindiquem as condições de trabalho [pesquisa] na educação básica, pois, como explica Franco (2011), ao vivenciar o cotidiano da instituição escolar e integrar-se ao coletivo da escola, esses estudantes terão a oportunidade de envolver-se mais profundamente no processo educativo e nas ações do ambiente escolar. Dessa forma, eles conviverão com a realidade condizente, o que poderá resultar em uma formação mais significativa, contribuindo para a construção da identidade profissional dos futuros professores. Além disso, segundo a mesma autora (2013), a Didática convidará os futuros professores a refletir sobre as atitudes frente à realidade, a respeito do significado do ato de ensinar e acerca das circunstâncias dadas, o que os levará a pensar naquele que receberá o ensino, passiva ou ativamente.

No tocante às atividades para essa disciplina, como apoio ao aprendente nas vivências de ensino/aprendizagem, as aulas específicas de Didática devem ser "[...] espaço privilegiado de encontro e de ações, [...], construida, feita pela ação conjunta de professores e alunos" (PIMENTA; ANASTASIOU, 2002, p. 207, grifos das au- 
toras). Por isso, sugere-se estudos sobre o campo da Didática como elemento mediador dos processos ensino e aprendizagem, elaboração e aplicação de projetos interventivos para essas mesmas escolas, assim como, doravante, a socialização e publicação das pesquisas desenvolvidas nas referidas escolas, entre outras.

A relação entre a disciplina de Didática, a universidade e o contexto escolar, deve possibilitar aos estudantes das licenciaturas saírem mais preparados para o exercício da profissão docente, com um nível cultural mais elevado, com as competências pessoais e profissionais necessárias para enfrentar as mudanças e os desafios gerais que estão postos pela sociedade contemporânea à docência. Quando se trata da formação inicial dos professores, portanto, fazem-se necessárias interações sociais e laços cada vez mais fortes entre a Didática, a universidade e o contexto escolar, pois os professores precisam de um processo de formação, seja a formação inicial ou contínua, que os instiguem a ser sujeitos e não objetos dessa formação.

\section{Considerações finais}

Para que a ação de ensinar-aprender seja formativa e transformadora, ela necessita estar articulada à Pedagogia. Precisa dos contributos teóricos-metodológicos da Didática. Exercer a docência, por consequência, implica ser mediador dos processos de ensino e aprendizagem como prática social, de emancipação política e transformação social. O papel da disciplina de Didática, nessa perspectiva, de modo articulado ao contexto escolar, enquanto campos indissociáveis, consiste em levar os estudantes das licenciaturas a problematizar sua formação e a situá-los em um contexto teórico -prático mais amplo acerca do seu saber e saber-fazer, com vistas a (re)pensar formas de transformação de suas (futuras e atuais) práticas pedagógicas.

Nesse processo de formação dos professores, da ação-reflexão, reflexão-ação, ação-reflexão-ação, da articulação entre a universidade e as escolas básicas por meio do ensino da Didática como ins- 
trumento político, os processos de ensino e aprendizagem adquirem novas configurações e a formação docente, novas perspectivas.

A relação entre a disciplina de Didática, a universidade e o contexto escolar, constitui potencial para elevar a qualidade da formação dos professores e, como desdobramento, da educação básica. Uma formação teórica e prática de qualidade para os professores implica necessariamente uma estreita relação entre o estudar e o fazer cujo resultado deve ser um saber-fazer docente com consciência a partir do seu próprio fazer pedagógico. Trata-se da reflexão crítica da prática como subsídio para a (auto)formação docente.

Os estudantes das licenciaturas e todos os professores, portanto, para terem uma formação/atuação digna, necessitam adotar princípios consistentes da Pedagogia enquanto ciência da/para a educação.

Considerando a discussão empreendida, a disciplina de Didática e as escolas básicas apresentam-se, então, como contextos complementares que, rigorosa e reflexivamente, possibilitarão a interligação entre teoria e prática. A Didática, por sua vez, necessita cada vez mais dialogar com as peculiaridades dos processos de ensino e aprendizagem que cotidianamente ocorrem no interior das escolas públicas brasileiras.

\section{Referências}

ARANHA, Antônia Vitória Soares; SOUZA, João Valdir Alves de. As licenciaturas na atualidade: nova crise? Educar em Revista, Curitiba, Brasil, n. 50, p. 69-86, out./dez. 2013. Editora UFPR. Disponível em: < http://revistas.ufpr.br/educar/ article/viewFile/34745/21530>. Acesso em: $1^{\circ}$. jul. 2017.

ARAÚJO, Osmar Hélio Alves; RODRIGUES, Janine Marta Coelho. A formação contínua dos professores e as avaliações externas no contexto educacional brasileiro. Imagens da Educação, v. 8, n. 1, p. 1-13, 2018. Disponível em: < https://doi. org/10.4025/imagenseduc.v8i1.40831 >. Acesso em: 20 mar. 2018.

ARAÚJO, Osmar Hélio Alves; RODRIGUES, Janine Marta Coelho; ARAGÃO, Wilson Honorato. O (des) lugar da pedagogia e da didática na formação dos professores. Revista online de Política e Gestão Educacional, Araraquara, v. 
21, n. 1, p. 215-226, 2017. Disponível em: <http://dx.doi.org/10.22633/rpge. v21.n.1.2017.9534>. Acesso em: 24 jun. 2017.

CANDAU, Vera Maria. Ensinar - aprender: desafios atuais da profissão docente. Revista COCAR, Belém, Edição Especial N. 2, p. 298 a 318 - ago./dez. 2016. Disponível em: <https://paginas.uepa.br/seer/index.php/cocar/article/ view/1035>. Acesso em: 24 jun. 2017.

FRANCO, Maria Amélia Santoro. Didática: uma esperança para as dificuldades pedagógicas do Ensino superior? Práxis Educacional, v. 9, n. 15, 2013. Disponível em: <http://periodicos.uesb.br/index.php/praxis/article/view/1947>. Acesso em: 4 maio 2016.

FRANCO, Maria Amélia Santoro. Pedagogia como ciência da educação, 2. ed. Rev. Ampl. São Paulo: Cortez, 2008.

FRANCO, Maria Amélia Santoro. Práticas pedagógicas de ensinar-aprender: por entre resistências e resignações. Educ. Pesqui. São Paulo, v. 41, n. 3, p. 601-614, jul./set. 2015. Disponível em: <http://www.scielo.br/pdf/ep/v41n3/1517-9702ep-41-3-0601>.pdf. Acesso em: 3 maio 2016.

FRANCO, Maria Amélia Santoro; GILBERTO, Irene Jeanete Lemos. A PRÁTICA DOCENTE E A CONSTRUÇÃO DOS SABERES PEDAGÓGICOS. Revista Teias v. 12, n. 25 • 212-224 • mai./ago. 2011 - Ética, Saberes \& Escola. Disponível em: <http://www.periodicos.proped.pro.br/index.php/revistateias/article/ view/705>. Acesso em: 2 maio 2016.

FREITAS, Luiz Carlos de. Os reformadores empresarias da educação e a disputa pelo controle do processo pedagógico na escola. Educ. Soc., Campinas, v. 35, n. 129, p. 1.085-1.114, out./dez. 2014. Disponível em: http:<//www.scielo.br/pdf/es/ v35n129/0101-7330-es-35-129-01085.pdf>. Acesso em: 13 jul. 2016.

GATTI, Bernadete A. Educação, escola e formação de professores: políticas e impasses. Educar em Revista, Curitiba, Brasil, n. 50, p. 51-67, out./dez. 2013. Editora UFPR. Disponível em: <http://www.scielo.br/pdf/er/n50/n50a05.pdf>. Acesso em: 24 abr. 2017.

LIBÂNEO, José Carlos. Adeus professor, adeus professora? Novas exigências educacionais e profissão docente, 10. ed. São Paulo: Cortez Editora, 2007.

LIBÂNEO, José Carlos. Democratização da Escola Pública: a pedagogia crítico-social dos conteúdos. São Paulo: Loyola, 2008. 
PEREIRA, Júlio Emilio Diniz. As licenciaturas e as novas políticas educacionais para a formação docente. Educação e Sociedade, Campinas, v. 20, n. 68, 1999.

PIMENTA, Selma Garrido. Pesquisa-ação crítico-colaborativa: construindo seu significado a partir de experiências com a formação docente. Educação e Pesquisa, São Paulo, v. 31, n. 3, p. 521-539, set./dez. 2005. Disponível em:

$<$ http://www.unifra.br/professores/13709/selma\%20pimenta.pdf >. Acesso em: 28 abr. 2017.

RIOS, Terezinha Azerêdo. Ampliar o diálogo de saberes para a docência. In: FRANCO, Maria Amélia Santoro; PIMENTA, Selma Garrido (Orgs.). DIDÁTICA: embates contemporâneos, 3. ed. São Paulo: Edições Loyola, 2014, p. 101-130.

Universidade Regional do Cariri (URCA) Pró-Reitoria de Ensino de Graduação. Departamento de Línguas e Literaturas (Curso de Letras), Campus de Missão Velha (CE). Projeto político pedagógico, 2013. Disponível em: < http://pt.calameo.com/books/0022775289ee54dd0d3c9 >. Acesso em: 23 jun. 2016.

Submetido em: 25-8-2016

Aceito em: 14-3-2018 